\title{
Precipitation, Recrystallization, and Evolution of Annealing Twins in a Cu-Cr-Zr Alloy
}

\author{
Xiaobo Chen ${ }^{1,2}$, Feng Jiang ${ }^{1,2,3,4, *}$, Jingyu Jiang ${ }^{1,2}$, Pian $\mathrm{Xu}^{2,3}{ }^{\circledR}$, Mengmeng Tong ${ }^{1,2}$ \\ and Zhongqin Tang 2,3 (i) \\ 1 School of Materials Science and Engineering, Central South University, Changsha 410083, China; \\ rewillcsu@hotmail.com (X.C.); csu_msejiang@hotmail.com (J.J.); csu_tong@hotmail.com (M.T.) \\ 2 Key Laboratory of Ministry of Education for Non-ferrous Materials Science and Engineering, Central South \\ University, Changsha 410083, China; xupian@hotmail.com (P.X.); csu_tzq816@hotmail.com (Z.T.) \\ 3 Light Alloy Research Institute, Central South University, Changsha 410083, China \\ 4 Science and Technology on High Strength Structural Materials Laboratory, Changsha 410083, China \\ * Correspondence: jfeng2@csu.edu.cn; Tel.: +86-731-8887-7693
}

Received: 14 February 2018; Accepted: 27 March 2018; Published: 1 April 2018

\begin{abstract}
In this paper, the precipitation, recrystallization, and evolution of twins in $\mathrm{Cu}-\mathrm{Cr}-\mathrm{Zr}$ alloy strips were investigated. Tensile specimens were aged at three different temperatures for various times so as to bring the strips into every possible aging condition. The results show that the appropriate aging parameter for the $70 \%$ reduced cold-rolled alloy strips is $723 \mathrm{~K}$ for $240 \mathrm{~min}$, with a tensile strength of $536 \mathrm{MPa}$ and an electrical conductivity of $85.3 \%$ International Annealed Copper Standards (IACS) at the peak aged condition. The formation of fcc (face-centered cubic) ordered Cr-rich precipitates $\left(\beta^{\prime}\right)$ is an important factor influencing the significant improvement of properties near the peak aged condition. In terms of crystallographic orientation relationships, there are basically two types of $\beta^{\prime}$ precipitates in the alloy. Beyond the Cr-rich precipitates $\left(\beta^{\prime}(\mathrm{I})\right)$ formed during the early aging stages, which mimic a cube-on-cube orientation relationship (OR) with the matrix, another $\mathrm{Cr}$-rich precipitate $\left(\beta^{\prime}(\mathrm{II})\right)$ is observed in the peak aged condition. $\beta^{\prime}(\mathrm{II})$ is coherent with the matrix, with the following ORs: $[111]_{\beta^{\prime}(\mathrm{II})} / /[100]_{\mathrm{Cu}}$, $\{02-2\}_{\beta^{\prime}(\mathrm{III})} / /\{02-2\}_{\mathrm{Cu}}$ and $[011]_{\beta^{\prime}(\mathrm{II})} / /[211]_{\mathrm{Cu}},\{200\}_{\beta^{\prime}(\mathrm{II})} / /\{-111\}_{\mathrm{Cu}}$. These precipitates have a strong dislocation and grain boundary pinning effect, which hinder the dislocation movement and crystal boundary migration, and eventually delay recrystallization and enhance the recrystallization resistance of the peak aged strips. During the subsequent annealing process, the transition phase $\beta^{\prime}$ gradually loses the coherence mismatch and grows into a larger equilibrium phase of chromium with a bcc (body-centered cubic) structure ( $\beta$ ), resulting in the reduction of the pinning effect to dislocations and sub-grains, so that recrystallization occurs. Annealing twins are formed during the recrystallization process to release the deformation energy and to reduce the drive force for interface migration, eventually hindering grain growth.
\end{abstract}

Keywords: $\mathrm{Cu}-\mathrm{Cr}-\mathrm{Zr}$; precipitation; orientation relationship; recrystallization; annealing twins

\section{Introduction}

Copper and its alloys are widely used in automobile, electronic, and electric power industries due to their high strength, high thermal and electrical conductivity, and good ductility, as well as because they can be easily shaped [1-6]. To satisfy applications in the frame materials in large-scale integrity circuits, besides the requirement of high strength and high electrical conductivity, excellent recrystallization resistance is also needed. $\mathrm{Cu}-\mathrm{Cr}-\mathrm{Zr}$ might be able to satisfy these requirements. Extensive literature is available on the microstructures, physical properties, and mechanical properties of $\mathrm{Cu}-\mathrm{Cr}-\mathrm{Zr}$ alloys [6-13]. From the literature, cold working and aging treatment are considered to be the two most 
important materials-processing techniques for $\mathrm{Cu}-\mathrm{Cr}-\mathrm{Zr}$ alloys. Fiber and banded structures can be formed during the cold work process, resulting in an increase of strength and hardness. The strength and electrical conductivity can be further improved via aging treatment through the formation of second phase precipitation. The precipitation of binary $\mathrm{Cu}-\mathrm{Cr}$ alloys is well studied. The main strengthening phase formed during the aging process is the equilibrium phase of chromium $(\beta)$ with a body-centered cubic structure (bcc, $a=0.2895 \mathrm{~nm}$ ). No transition phase is observed at the early aging stage [14,15]. There is a general agreement about the fact that a transition phase $\beta^{\prime}$ is formed during the ternary $\mathrm{Cu}-\mathrm{Cr}-\mathrm{Zr}$ alloy aging process $[16,17]$. Nevertheless, the structure and orientation of the precipitated phase has not yet formed a consistent theory. Tang et al. [16] reported that, for $\mathrm{Cu}-\mathrm{Cr}-\mathrm{Zr}-\mathrm{Mg}$ alloys, the peak hardness was associated with the fine scale of an ordered compound, possibly of the Heusler type, with the suggested composition of $\mathrm{CrCu}_{2}(\mathrm{Zr}, \mathrm{Mg})$ and a face-centered cubic (fcc) crystal structure with a large unit cell containing $8 \mathrm{Cu}, 4 \mathrm{Cr}$, and $4 \mathrm{Zr}$ or $4 \mathrm{Mg}$. This unit cell can be regarded as containing $8 \mathrm{bcc}$ sub-cells with each housing a $\mathrm{Cu}$ atom at its center and $\mathrm{Cr}, \mathrm{Zr}$, or $\mathrm{Mg}$ atoms alternatively occupying the corners. This Heusler type $\left(\mathrm{CrCu}_{2}(\mathrm{Zr}, \mathrm{Mg})\right)$ phase was also reported by Liu et al. [18], Qi et al. [19], and Su et al. [20]. Using multi-angle electron diffraction, Batra et al. [21] proved the existence of a transition fcc structure Cr-rich phase with a cube-on-cube OR during the early aging stage. This kind of fcc structure was also observed by Xia et al. [22] and Chen et al. [23]. Moreover, other precipitation phases have also been observed, like $\mathrm{Cu}_{4} \mathrm{Zr}$ [16] or $\mathrm{Cu}_{51} \mathrm{Zr}_{14}$ [24], and some $\mathrm{Zr}$ and Fe segregations along $\mathrm{Cu} / \mathrm{Cr}$ interfaces [25] have also been reported. As discussed above, the transition phases have not yet been elucidated. As a result, it is of great importance to elucidate the structure of the precipitates, especially the structure of the phases formed during peak aged conditions.

A high operating temperature can be achieved for the application of frame materials in large-scale integrity circuits, making the recrystallization resistance of great importance for the successful application in the frame materials. However, only very few reports are available to discuss the recrystallization resistance behavior as well as the mechanism of $\mathrm{Cu}-\mathrm{Cr}-\mathrm{Zr}$ alloys. Liu et al. [18] studied the aging process of $\mathrm{Cu}-\mathrm{Cr}-\mathrm{Zr}-\mathrm{Mg}$ alloys prepared via the rapid solidification method. Recrystallization occurred and the precipitates kept coarsening when aged at $723 \mathrm{~K}$ for $240 \mathrm{~h}$. Su et al. [26] reported that when the temperature exceeded $773 \mathrm{~K}$, recrystallization occurred in a $45 \%$ cold-rolled Cu-Cr-Zr-Mg alloy, while the precipitates coarsened at the same time. These reports clearly suggest that the recrystallization resistance properties of $\mathrm{Cu}-\mathrm{Cr}-\mathrm{Zr}$ alloys are related to the coarsening of the precipitates. This is necessary to elucidate the evolution of the precipitation as well as the microstructure in order to facilitate the preparation of highly recrystallization-resistant $\mathrm{Cu}-\mathrm{Cr}-\mathrm{Zr}$ alloys.

In this work, we studied the evolution of precipitation, recrystallization, and twins during the heat treatment process in a Cu-Cr-Zr alloy. We identified the crystal structure and the orientation relationships of the strengthening phases at the peak aged condition. In addition, the corresponding precipitation strengthening effect and recrystallization resistance mechanism were discussed.

\section{Experiments}

The chemical composition of the hot-rolled $\mathrm{Cu}-\mathrm{Cr}-\mathrm{Zr}$ alloy employed in this work is as follows (wt \%): 0.80-Cr, 0.20-Zr, and $\mathrm{Cu}$ balance (Bal.). The initial hot-rolled sheet was $50 \mathrm{~mm}$ in thickness. After solution heat treatment at $1253 \mathrm{~K}$ for $60 \mathrm{~min}$ and after quenching with water, the sheet was cold-rolled to $1.5 \mathrm{~mm}$ with a reduction ratio of about $70 \%$. The cold-rolled sheet was isothermally aged at $673 \mathrm{~K}, 723 \mathrm{~K}$, and $773 \mathrm{~K}$ for various lengths of time. Tensile strength and electrical conductivity measurements were carried out to determine the best aging condition. Afterwards, the best aged sample was treated by stabilization annealing from $573 \mathrm{~K}$ to $973 \mathrm{~K}$ with a temperature interval of $50 \mathrm{~K}$ for $60 \mathrm{~min}$.

Tensile tests were performed on a CSS-44100 electronic universal testing machine (Sinotest Equipment Co. Ltd., Changchun, China) and carried out at room temperature with a tensile speed of $2 \mathrm{~mm} / \mathrm{min}$. Hardness (HB) was tested with an HBE-3000 type digital Brinell hardness (Guangzhou material Testing Machine Factory, Guangzhou, China) with a 25-kg load and a 30-s loading time. 
The electrical conductivity was measured via an eddy current conductivity meter (Xiamen Xin Bote science and Technology Co. Ltd., Xiamen, China) under a work frequency of $60 \mathrm{kHz}$. The resistivity was calculated and transformed into electrical conductivity according to International Annealed Copper Standards (IACS).

Specimens for optical microscopy (OM) observations were polished and etched in a solution of $10 \%$ potassium dichromate, $5 \%$ sulfuric acid, and $85 \%$ distilled water, and performed on a LEICA EC3 optical microscope (Nanjing Jiangnan Novel Optics Co. Ltd., Nanjing, China) equipped with a digital camera. Samples for transmission electron microscopy (TEM) observations were prepared via double jet electropolishing techniques. The electrolyte consisted of 30\% nitric acid in methanol and the solution was maintained at a temperature between $243 \mathrm{~K}$ and $253 \mathrm{~K}$. The TEM images and selected area electron diffraction (SAED) were taken by an FEI Tecnai G2 20 transmission electron microscope (FEI, Hillsboro, OR, USA) operating at $200 \mathrm{kV}$. TEM samples from all conditions were prepared from the center of the tensile or hardness test samples in a direction parallel to the rolling direction. The aged or annealed samples were cooled in air. To investigate areas of the partly recrystallized samples, the techniques of electron backscatter diffraction (EBSD) in a scanning electron microscopy (SEM) (FEI, Hillsboro, OR, USA) were applied. The local orientation measurements were investigated by a Sirion 200 Field-Emission Scanning Electron Microscope (FEI, Hillsboro, OR, USA). The EBSD measurements were carried out at an accelerating voltage of $20 \mathrm{kV}$ and a scan step of $0.2 \mu \mathrm{m}$. The results were analyzed via orientation image microscopy (OIM) analysis software.

\section{Results}

\subsection{Properties}

Figure 1 shows the influence of the aging time on both the tensile strength (Figure 1a) and electrical conductivity (Figure 1b) of the studied alloy. It can be observed that tensile strength and electrical conductivity increase rapidly during the early stage of aging as the second phase particles rapidly form in the matrix. It can also be seen that the time required to reach peak strength decreases with the increasing aging temperature (Figure 1a). On the other hand, it can also be observed that, when the aging temperature is increased to $773 \mathrm{~K}$, the tensile strength in the peak aged condition is lower than that of aging at $723 \mathrm{~K}$. As shown in Figure 1b, the electrical conductivity can reach to above $80 \%$ IACS, when aged at $723 \mathrm{~K}$ or $773 \mathrm{~K}$. An excellent combination of those properties, such as a tensile strength of $536 \mathrm{MPa}$ and an electrical conductivity of $85.3 \%$ IACS, is obtained in the Cu-Cr-Zr alloy aged at $723 \mathrm{~K}$ for $240 \mathrm{~min}$ (minimum). The most suitable aging condition is considered to be one where good combinations of strength and conductivity can be obtained after aging. As a result, the optimized aging treatment for this alloy is $723 \mathrm{~K}$ for $240 \mathrm{~min}$.

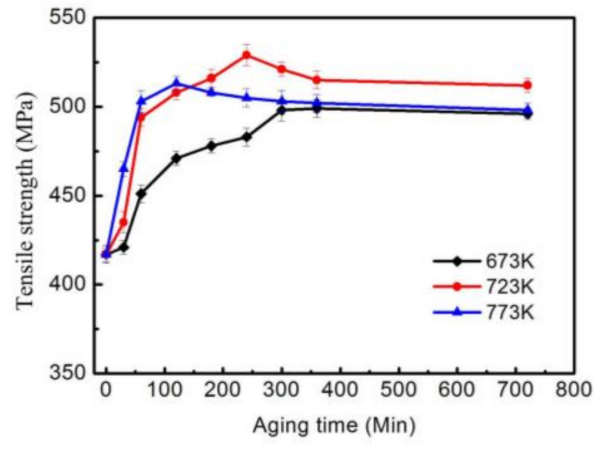

(a)

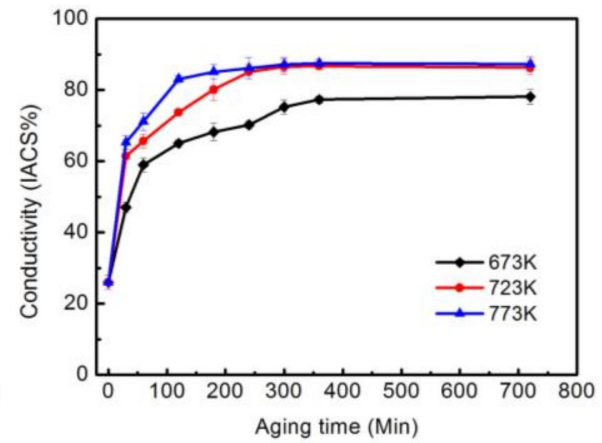

(b)

Figure 1. (a) Tensile strength and (b) electrical conductivity of the $\mathrm{Cu}-\mathrm{Cr}-\mathrm{Zr}$ alloy as a function of aging time at various temperatures. 
Figure 2 shows the hardness of the peak aged samples after annealing at different temperatures for $60 \mathrm{~min}$. The hardness in the peak aged condition is $163 \mathrm{HB}$. When the annealing temperature is lower than $773 \mathrm{~K}$, the hardness of the alloy can be kept at a high value. The hardness of the alloy begins to decrease rapidly when the annealing temperature is above $773 \mathrm{~K}$. After annealing at $823 \mathrm{~K}$, the decrease in hardness is significant, and the hardness is $143 \mathrm{HB}$, about $87.4 \%$ of the unannealed sample. The hardness of the alloy continues to decrease as the temperature increases. When the annealing temperature increases to $873 \mathrm{~K}$, the hardness is $131 \mathrm{HB}$, just about $80.4 \%$ of the unannealed sample.

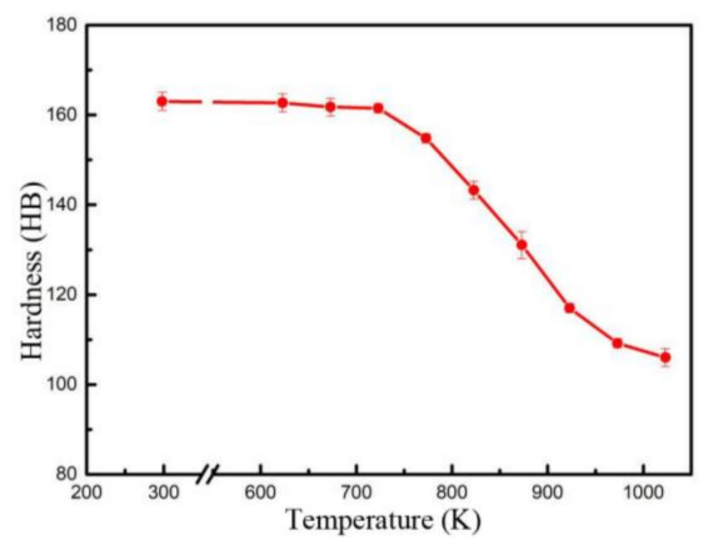

Figure 2. The hardness of the $\mathrm{Cu}-\mathrm{Cr}-\mathrm{Zr}$ alloy as a function of the peak age samples after annealing at different temperatures for $60 \mathrm{~min}$.

\subsection{Microstructure}

Figure 3 shows OM micrographs of differently treated $\mathrm{Cu}-\mathrm{Cr}-\mathrm{Zr}$ alloys. Typical cold rolling deformation characteristics are still retained in the peak aged samples, as shown in Figure 3a. The grains are elongated and wavy along the rolling direction. Figure $3 b, c$ show the structure of the peak aged samples after annealing at different temperatures. Clear recrystallized grains are observed in the samples after annealing at $873 \mathrm{~K}$, as shown in Figure 3b. After annealing at $973 \mathrm{~K}$, a full recrystallized structure is observed, as shown in Figure 3c. The grain size is uniform, with an average grain size of about $10 \mu \mathrm{m}$, and no obvious grain growth is observed.

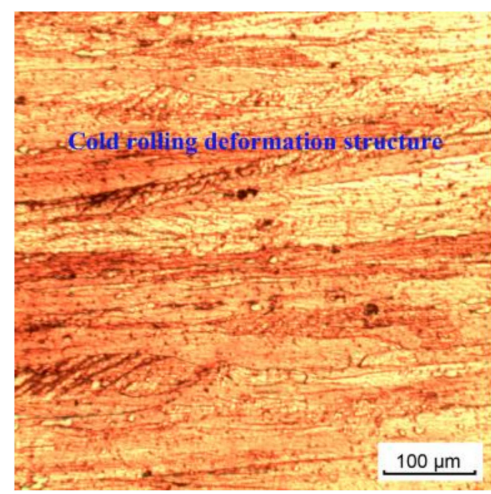

(a)

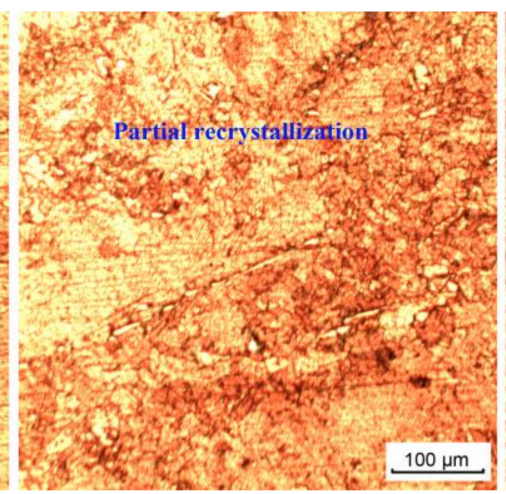

(b)

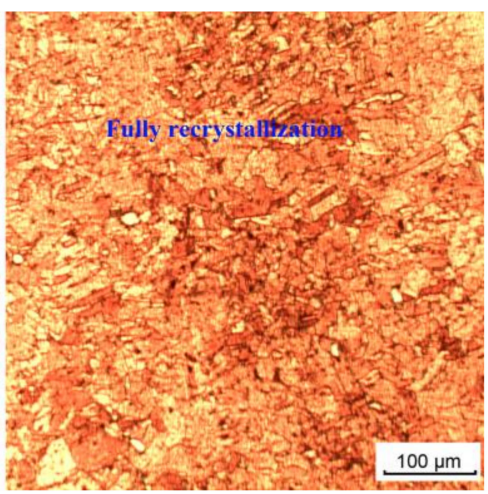

(c)

Figure 3. Optical microscopy (OM) micrographs of $\mathrm{Cu}-\mathrm{Cr}-\mathrm{Zr}$ alloys with 240 -min-aged initial states at (a) $723 \mathrm{~K}$, and 60-min-annealed states at different temperatures of (b) $873 \mathrm{~K}$ and (c) $973 \mathrm{~K}$.

Figure 4 shows the bright-field (BF) image of $\mathrm{Cu}-\mathrm{Cr}$ - $\mathrm{Zr}$ alloys in different heat treatment conditions. The grains are deformed to different degrees after heavy cold rolling, resulting in the formation of 
different deformation zones. A large number of dislocations are intertwined to form dislocation walls or dislocation transition zones. There are generally two types of boundaries that form and evolve via heavy cold rolling. These boundaries have been termed geometrically necessary boundaries (GNBs) and incidental dislocation boundaries (IDBs), where GNBs form between regions of different strain patterns to accommodate the accompanying difference in lattice rotation, and IDBs form via the random trapping of dislocations [27]. After the aging treatment, the dislocations are rearranged to form small dislocation cells, and the dislocation cells aggregate in the dislocation cell walls, resulting in the decrease of the dislocation density inside the dislocation cells. The IDBs in the local shear zone start to evolve into small angle sub-grains with a size of $0.2-0.5 \mu \mathrm{m}$, as shown in Figure $4 \mathrm{a}$. After aging at $723 \mathrm{~K}$ for $240 \mathrm{~min}$, when the alloy is annealed at a temperature higher than $773 \mathrm{~K}$, the sub-grains are clearly changed. After annealing at $823 \mathrm{~K}$, well-developed sub-grains with a size of $0.2-0.5 \mu \mathrm{m}$ can be observed, accompanied by the weakening of GNBs and IDBs in the shear deformation zone (Figure $4 \mathrm{~b}$ ). After annealing at $873 \mathrm{~K}$, recrystallized grains are observed and the size is slightly larger than that of the sub-grains in Figure $4 \mathrm{~b}$. When the annealing temperature increases to $973 \mathrm{~K}$, the grain size in the alloy significantly grows and grain boundaries become straight and smooth (Figure 4d).

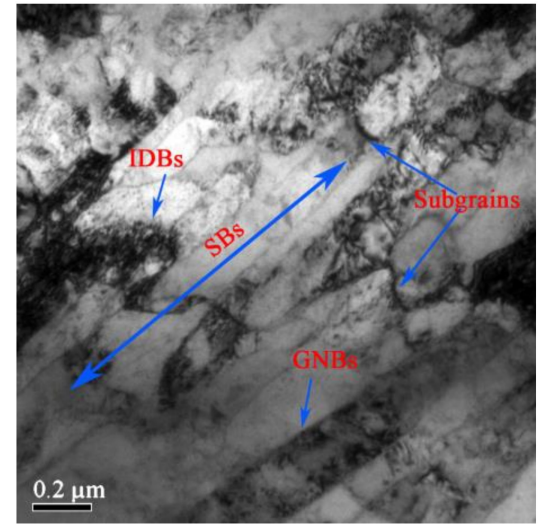

(a)

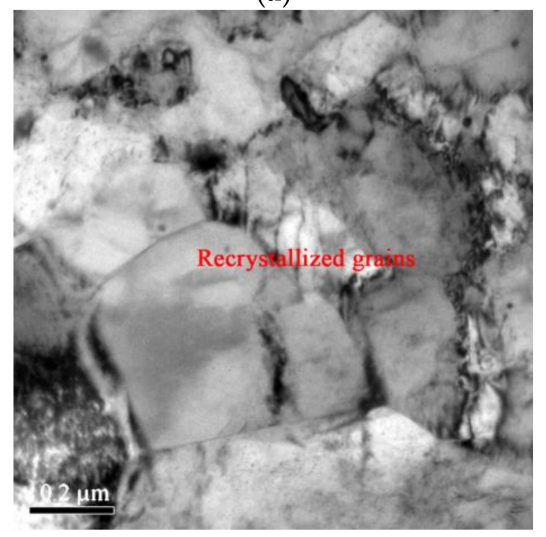

(c)

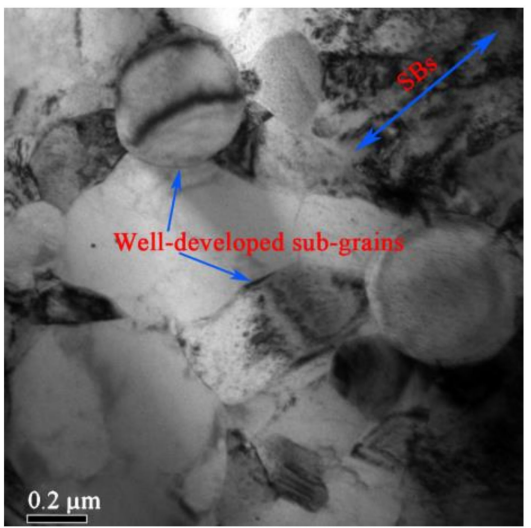

(b)

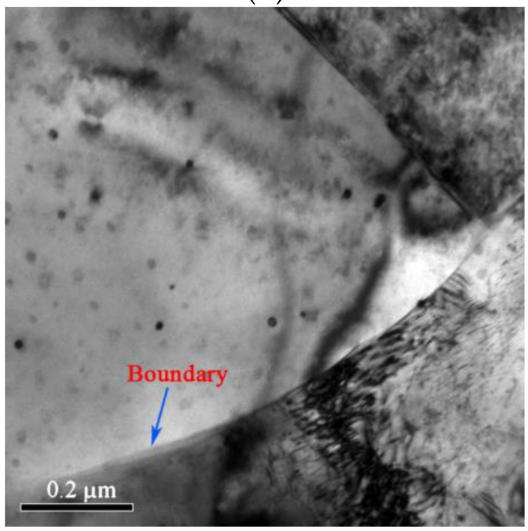

(d)

Figure 4. Bright-field (BF) images of Cu-Cr-Zr alloys with 240-min-aged initial states at (a) $723 \mathrm{~K}$, and 60-min-annealed states at different temperatures of (b) $823 \mathrm{~K}$, (c) $873 \mathrm{~K}$, and (d) $973 \mathrm{~K}$.

Figure 5 shows the BF and corresponding SAED patterns of the precipitates formed during aging. When aged at $723 \mathrm{~K}$ for $30 \mathrm{~min}$, very fine precipitates are observed with a weak contrast. According to high-magnification near-double beam observation, the precipitated phase entails spherical particles with a size of about $2 \mathrm{~nm}$, and there is a double leaf petal-like contrast, which suggests that the precipitate phase is coherent with the matrix, as shown in Figure 5a. Figure 5b shows the structure of the alloy after aging at $723 \mathrm{~K}$ for $240 \mathrm{~min}$. A large number of precipitates are observed, significantly enhancing the contrast. The size of the precipitates is slightly larger, about $4 \mathrm{~nm}$. A non-contrast line perpendicular 
to the manipulated vector is also observed, indicating that there is a coherent relationship between the precipitated particles and the matrix. From the SAED of the sample aged for $30 \mathrm{~min}$, a few superlattice spots can be observed in Figure 4c,d (marked by a triangle arrow). This is probably due to the enrichment of solute atoms on alternate $\{011\}$ planes [17]. Therefore, the precipitate is likely to have an ordered lattice structure. Diffraction spots from the precipitated particles are shown in Figure $4 \mathrm{c}, \mathrm{d}$, which indicates that the discontinuous precipitates are fcc $\mathrm{Cr}$-rich phases with a cube-on-cube OR (designated as $\beta^{\prime}(\mathrm{I})$ ). The result is also in accordance with previous studies on $\mathrm{Cu}-\mathrm{Cr}-\mathrm{Zr}$ alloys [17,21-23]. The precipitate lattice parameter is calculated to be about $0.4180 \mathrm{~nm}$. Figure 5e,f show the corresponding SAED of the sample aged for $240 \mathrm{~min}$ (peak aged). Superlattice reflections are also observed and the results indicate that the produced precipitates here are also ordered (marked by a triangle arrow). The SAED shows that these precipitates also have an fcc structure with a lattice constant of $0.4150 \mathrm{~nm}$ (designated as $\beta^{\prime}(\mathrm{II})$ ). The orientation relationship exhibited here is determined to be: $[211]_{\mathrm{Cu}} / /[011]_{\beta^{\prime}(\mathrm{II})},\{-111\}_{\mathrm{Cu}} / /\{200\}_{\beta^{\prime}(\mathrm{II})}$ and $[100]_{\mathrm{Cu}} / /[111]_{\beta^{\prime}(\mathrm{II})},\{02-2\}_{\mathrm{Cu}} / /\{02-2\}_{\beta^{\prime}(\mathrm{II})}$. The above results show that $\beta^{\prime}(\mathrm{II})$ has a lattice constant close to as well as an ordered structure with $\beta^{\prime}(\mathrm{I})$. As a result, it can be concluded that $\beta^{\prime}(\mathrm{II})$ and $\beta^{\prime}(\mathrm{I})$ are the same crystal structure with different orientation relationships to the matrix. The same precipitates formed during the aging process show a variety of interphase relationships confirmed in Cu-Ni-Si [28], Mg-Zn-Al [29], and Al-Mg-Si [30] alloys. Although the fcc precipitates have been reported, the existence of two orientation relationships for the transition phase $\beta^{\prime}$ is proposed and confirmed in this work for the first time, for $\mathrm{Cu}-\mathrm{Cr}-\mathrm{Zr}$ alloy after a cold-solution deformation-aging treatment.

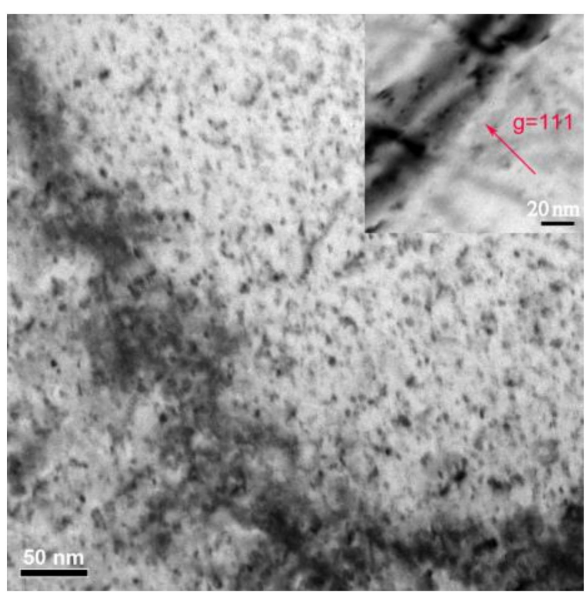

(a)

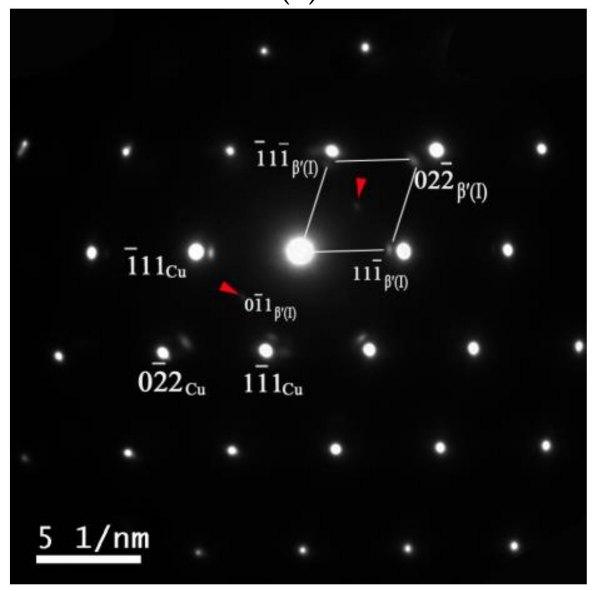

(c)

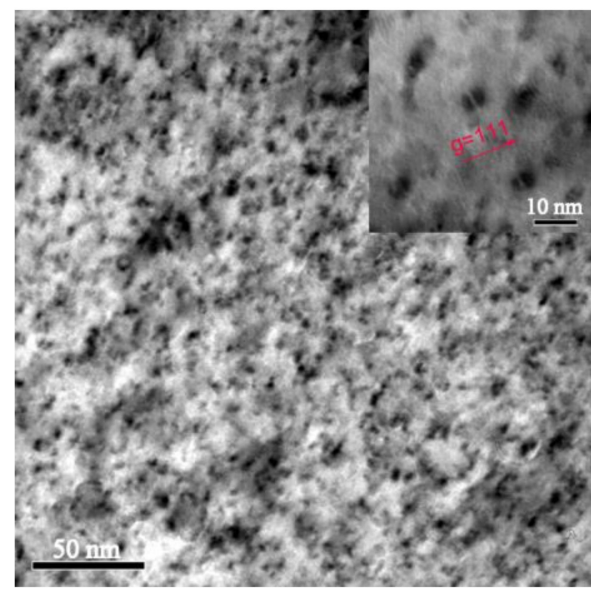

(b)

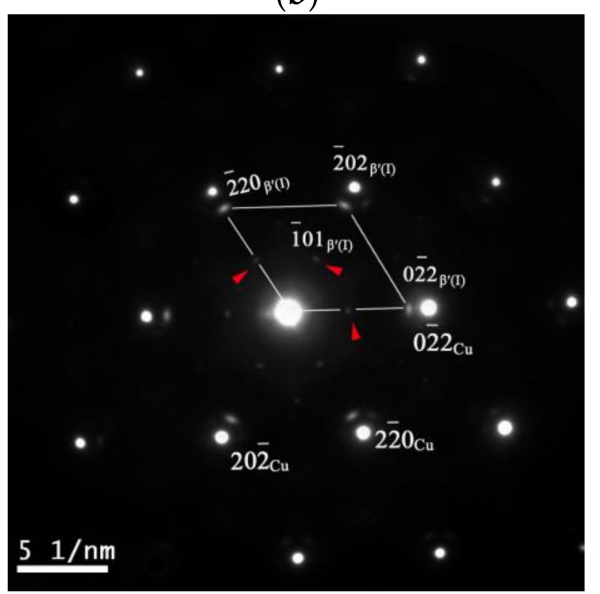

(d)

Figure 5. Cont. 


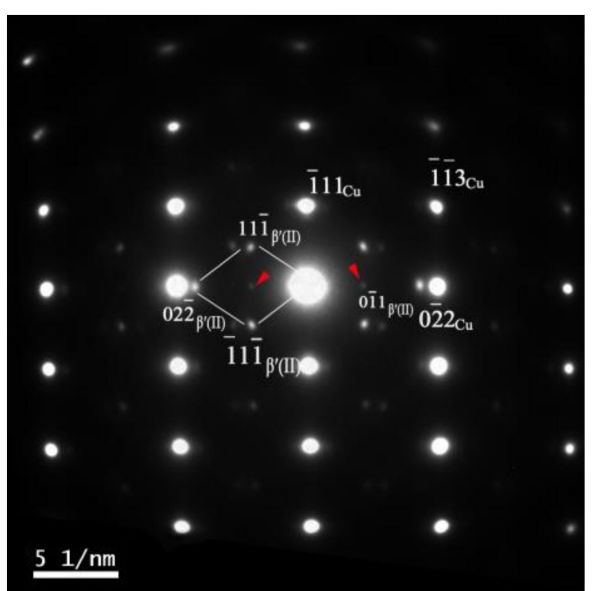

(e)

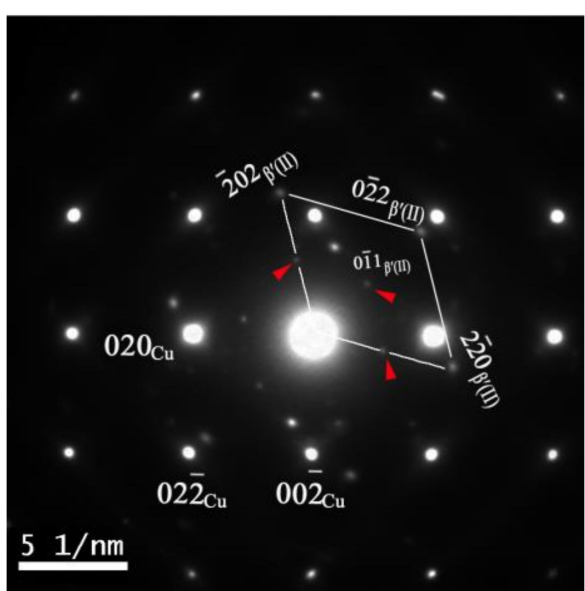

(f)

Figure 5. BF micrographs and selected area electron diffraction (SAED) patterns of the studied alloy aged at $723 \mathrm{~K}$ for various durations: (a) $30 \mathrm{~min}$ and (b) $240 \mathrm{~min}$. SAED patterns were taken from samples aged for $30 \mathrm{~min}$, from beams along the zone axis of: (c) [110] $]_{\mathrm{Cu}}$ and (d) [111] $]_{\mathrm{Cu}}$; and aged for $240 \mathrm{~min}$, from beams along the zone axis of: (e) [211 $]_{\mathrm{Cu}}$ and (f) $[100]_{\mathrm{Cu}}$.

Figure 6 shows the BF micrographs of the precipitates of the peak aged samples after annealing at different temperatures. As shown in Figure 6a, a large number of $\beta^{\prime}$ precipitates still exist in the alloy. The $\beta^{\prime}$ precipitates at the sub-grain boundary still exhibit a double petal-like contrast, indicating coherence with the matrix. The $\beta$ phase, having a larger size, can be clearly observed in the grain boundary, as shown in Figure $6 \mathrm{~b}$. This indicates that during the formation of the crystal boundary, the transition phase $\beta^{\prime}$ gradually loses coherence and grows into a larger equilibrium phase $\beta$. When the annealing temperature further increases to $873 \mathrm{~K}$, the precipitates all evolve to coarse $\beta$ particles, as shown in Figure $6 \mathrm{c}$. The size of the precipitates significantly increases, and precipitation-free zones form at the grain boundaries, as shown in Figure $6 \mathrm{~d}$.

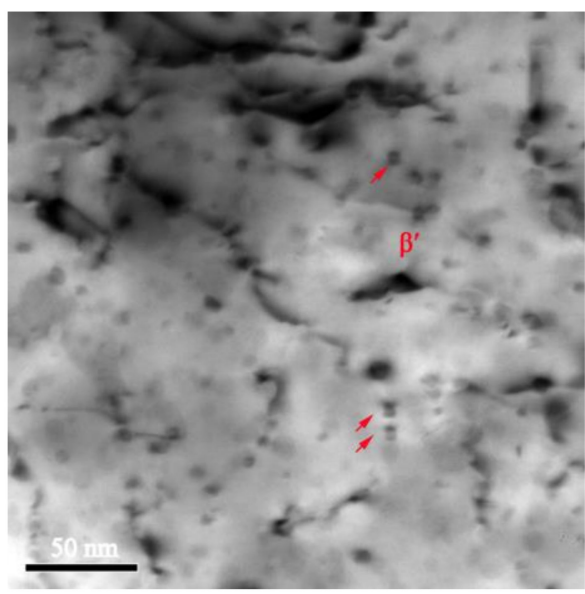

(a)

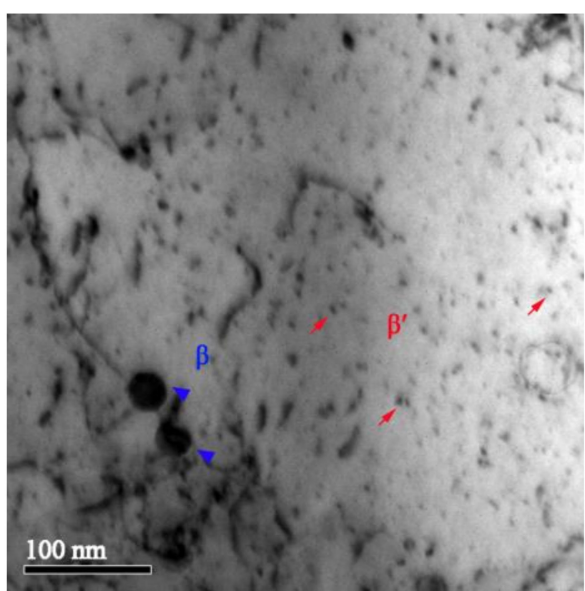

(b)

Figure 6. Cont. 


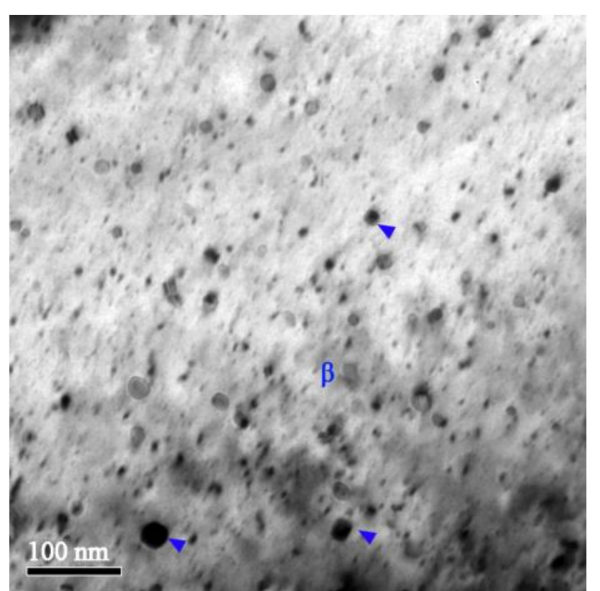

(c)

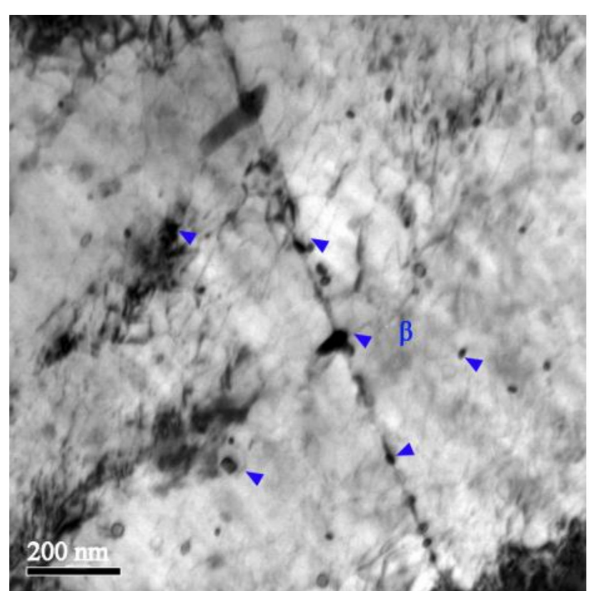

(d)

Figure 6. BF micrographs of $\mathrm{Cu}-\mathrm{Cr}-\mathrm{Zr}$ alloys with 60-min-annealed states at different temperatures: (a,b) $823 \mathrm{~K}$ and (c,d) $873 \mathrm{~K}$.

Figure 7 shows the micrographs of twins of the peak aged samples annealed at different temperatures. The growth of the recrystallized grains is accompanied by the formation of annealing twins. Figure $7 \mathrm{a}, \mathrm{b}$ show the BF images of annealing twins annealed at $873 \mathrm{~K}$. The twins formed inside the grains have two parallel twin boundaries which traverse the whole grain. The width of the twins is about $30 \mathrm{~nm}$ and only a few dislocations are observed inside the twins, as shown in Figure 7a. Besides the parallel twins, annealing twins are also formed at the grain boundaries of the recrystallized grains, as shown in Figure $7 \mathrm{~b}$. A high dislocation density is observed in these twins, whereas only a few dislocations were observed around these twins. When the annealing temperature increases to $973 \mathrm{~K}$, the twins grow significantly and the width can increase up to $200 \mathrm{~nm}$, as shown in Figure 7c. Some of the twins can grow in an intergranular way, and their growth is hindered when they meet coarse precipitates, as shown in Figure 7d. The growth of the twins not only forms parallel twins, but some stepped structures are also observed, as shown in Figure 7e. The SAED result in Figure 7c shows that the pattern belongs to typical twins in fcc metals [14]. The twin plane is $\{111\}$ and the direction is $<112>$, respectively. The zone axis between the matrix and the twin has a rotational symmetry of $180^{\circ}$ and can be considered as $[101]_{\mathrm{M}} / /[-10-1]_{\mathrm{T}}$ (M-Matrix, T-Twin), as shown in Figure $7 \mathrm{f}$.

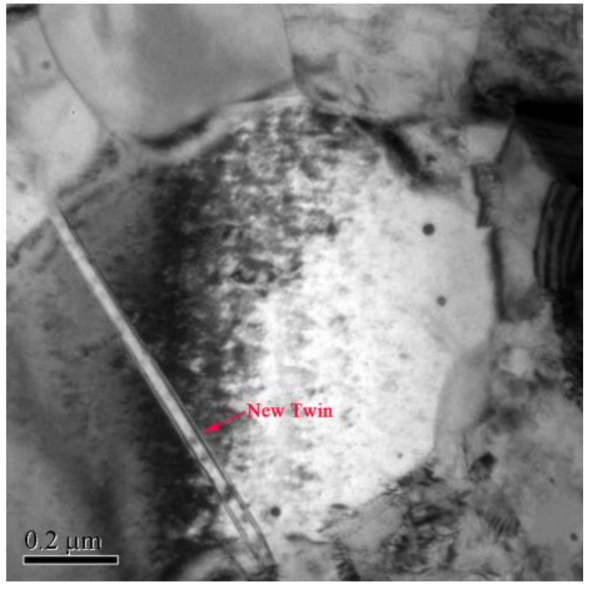

(a)

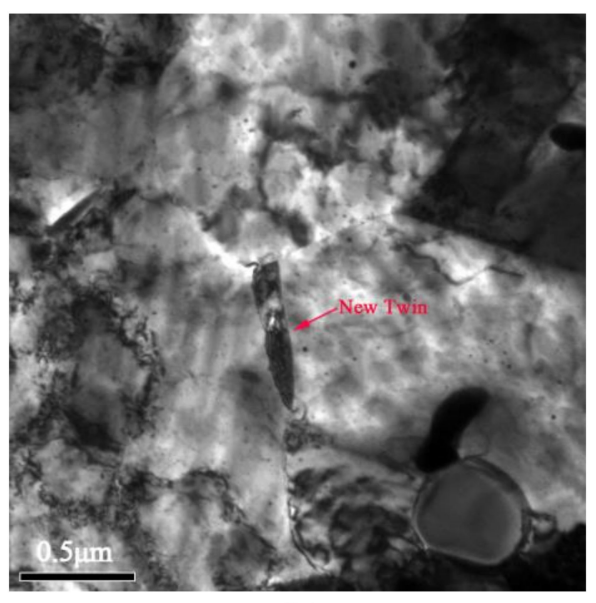

(b)

Figure 7. Cont. 


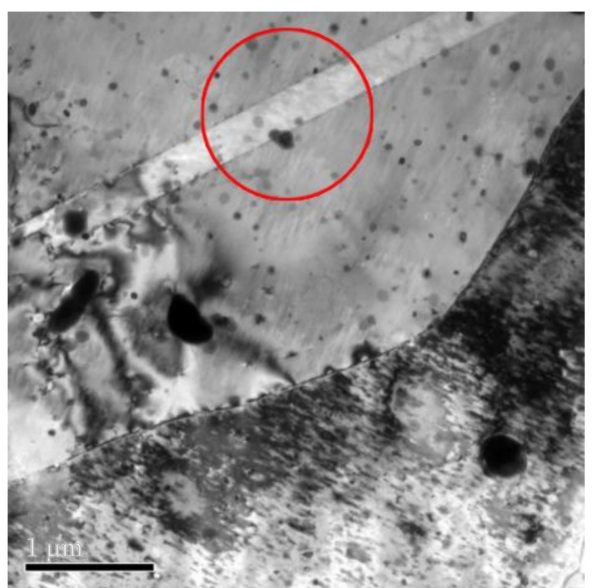

(c)

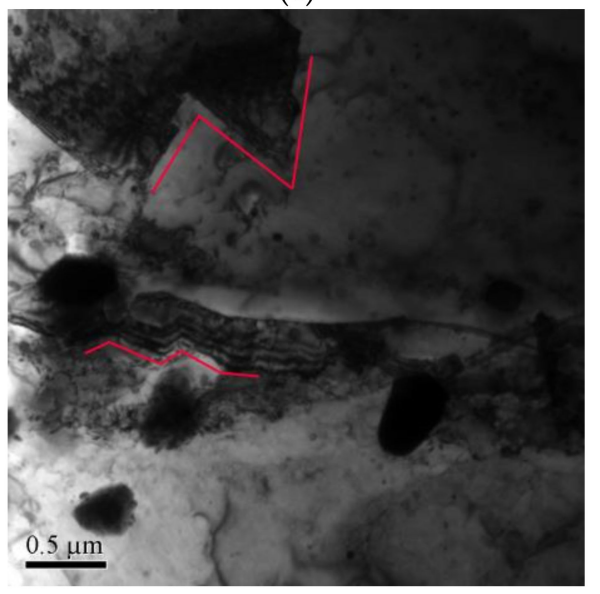

(e)

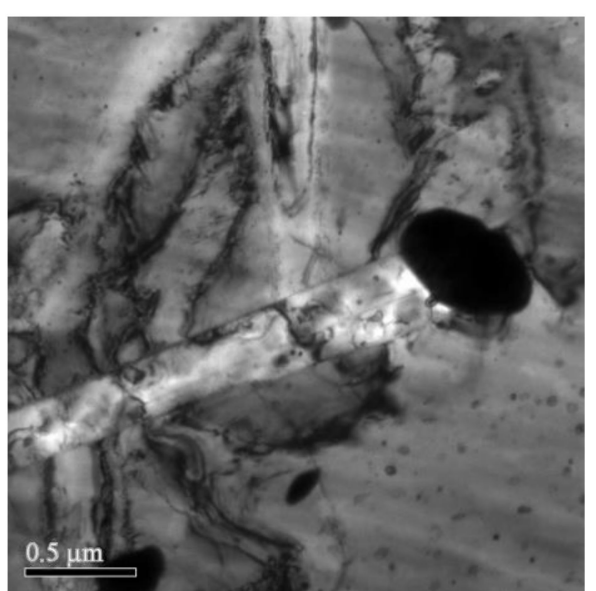

(d)

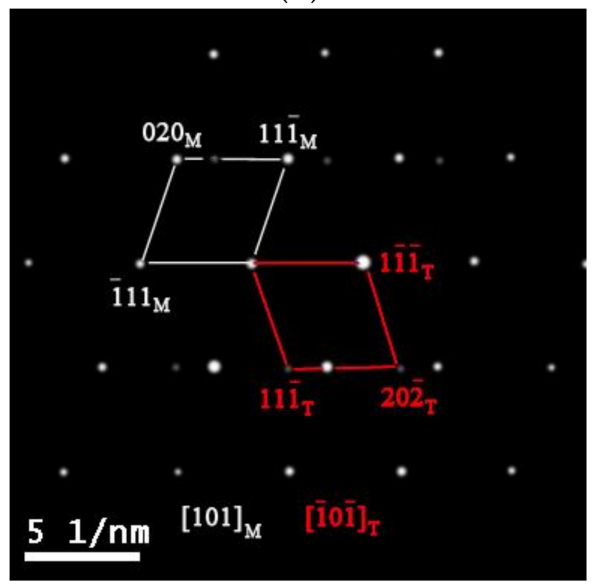

$(\mathbf{f})$

Figure 7. The BF and SAED of the twins of the studied alloy under different annealing temperatures: $(\mathbf{a}, \mathbf{b}) 873 \mathrm{~K}$ and (c-e) $973 \mathrm{~K}$; (f) the SAED of twins for the circular selection region in (c).

\section{Discussion}

\subsection{The Influence of the Precipitation on Strength and Conductivity}

TEM investigations of the precipitation reveal the presence of two types of $\beta^{\prime}$ phases with two crystal orientation relationships. Beyond the $\beta^{\prime}(\mathrm{I}) \mathrm{Cr}$-rich precipitates formed at the early stages of aging, which mimic a cube-on-cube OR with the matrix, other fcc-ordered $\mathrm{Cr}$-rich precipitates $\left(\beta^{\prime}(\mathrm{II})\right)$ were observed in the peak aged condition. $\beta^{\prime}(\mathrm{II})$ is coherent with the matrix, with the following orientation relationship with the Cu matrix: $[111]_{\beta^{\prime}(\mathrm{II})} / /[100]_{\mathrm{Cu}},\{02-2\}_{\beta^{\prime}(\mathrm{II})} / /\{02-2\}_{\mathrm{Cu}}$ and $[011]_{\beta^{\prime}(\mathrm{II})} / /[211]_{\mathrm{Cu}},\{200\}_{\beta^{\prime}(\mathrm{II})} / /\{-111\}_{\mathrm{Cu}} \cdot[110]_{\mathrm{Cu}}$ and [111 $]_{\mathrm{Cu}}$ are the best observation axes for the $\beta^{\prime}(\mathrm{I})$ phase, as shown in Figure $5 c, d$, and $[100]_{\mathrm{Cu}}$ and $[211]_{\mathrm{Cu}}$ are the best observation axes for the $\beta^{\prime}(\mathrm{II})$ phase, as shown in Figure 5e,f. Attempts $[10,25]$ to identify the composition of precipitates in this alloy have been only partially successful. Hatakeyama et al. [25] reported that $\mathrm{Cr}$ clusters enriched with $\mathrm{Zr}$ were observed at the prime aging stage, and further aging caused clusters to grow into Cr precipitates. Chbihi et al. [10] found that nano-scaled precipitates contained a large amount of $\mathrm{Cu}$. Following this, during the coarsening stage, precipitates transformed into bcc and progressively increased their $\mathrm{Cr}$ contents. As a result, based on our experimental results and previous reports, we assume that the transition phases were mainly composed of $\mathrm{Cu}$ and $\mathrm{Cr}$, as well as a small amount of $\mathrm{Zr}$. Moreover, only $\beta^{\prime}(\mathrm{I})$ precipitates formed after the initial aging at $723 \mathrm{~K}$ for $30 \mathrm{~min}$. Prolonged aging leads to the formation of $\beta^{\prime}(\mathrm{II})$ precipitates. After the completion of over-aging, only $\beta$ precipitates were detected in the matrix. This sequence is similar to that of Al-Mg-Si alloys [30]. Thus, the possible precipitation 
sequence of this alloy can be understood to be as follows: supersaturated solid solution $\rightarrow \beta^{\prime}(\mathrm{I}) \rightarrow$ $\beta^{\prime}$ (II) $\rightarrow \beta$, which is different from $\mathrm{Cu}-\mathrm{Cr}$ binary alloys, in which the sequence is a supersaturated solid solution $\rightarrow \beta$ [15]. As a result, we can conclude that the trace addition of $\mathrm{Zr}$ modified the precipitation mechanism and enhanced the age-hardening effects of the binary $\mathrm{Cu}-\mathrm{Cr}$ alloy. Watanabe et al. [31] proposed that $\mathrm{Zr}$ addition probably forms $\mathrm{Cu}_{5} \mathrm{Zr}$ precipitates, resulting in an increase in strength. Although some $\mathrm{Zr}$-rich phases have been observed, such as $\mathrm{Cu}_{4} \mathrm{Zr}$ [16], $\mathrm{Cu}_{51} \mathrm{Zr}_{14}$ [24], and $\mathrm{Cu}_{5} \mathrm{Zr}$ [31], the formation of $\mathrm{Zr}$-rich precipitates is not likely to be the main cause of the precipitation mechanism change nor the enhancement of the age-hardening effects in this study, because the reported Zr-rich precipitates are coarse phases and their content is low. It is also reported that $\mathrm{Zr}$ addition can increase the nucleation rate of $\mathrm{Cr}$-rich precipitates [32]. The nucleation barriers for fcc and bcc Cr-rich clusters are $3 \times 10^{-22} \mathrm{~J}$ and $4 \times 10^{-20} \mathrm{~J}$, respectively [10]. This fcc Cr-rich cluster can easily lose coherence due to high distortion and low stability, and can rapidly evolve into the equilibrium $\beta$ phase in binary alloys. However, in $\mathrm{Cu}-\mathrm{Cr}-\mathrm{Zr}$ alloys, $\mathrm{Zr}$ segregates to form the atmosphere of a nucleated cluster [25], which increases the stability of the $\mathrm{Cr}$-rich clusters and promotes the formation of the transition phase $\beta^{\prime}$, inhibiting the transformation from $\beta^{\prime}$ to $\beta$. However, to the authors' knowledge, the causes of this phenomenon remain unclear. The formation of a transition phase with an ordered structure is commonly observed in many systems where cascades of metastable phases are observed (e.g., AlMgSi [33-35] and CuNiSi [28,36]). For Al-Mg-Si alloys, whose precipitation sequence during aging is: $\alpha$ (ssss) $\rightarrow$ solute clusters $\rightarrow$ Guinier Preston (GP) zones $\rightarrow \beta^{\prime \prime} \rightarrow \beta^{\prime} \rightarrow \beta$, the $\beta^{\prime \prime}$ transition phase, which has an ordered structure, shows the best strengthening effect [37].

The strength of the $\mathrm{Cu}-\mathrm{Cr}-\mathrm{Zr}$ alloy approaches its peak and the conductivity reaches a high and stable value after aging at $723 \mathrm{~K}$ for $240 \mathrm{~min}$. A significant improvement in the strength of the $\mathrm{Cu}-\mathrm{Cr}-\mathrm{Zr}$ alloy is obtained after the aging treatment due to the precipitation, which drains the dissolved solute atoms from the copper matrix by forming nano-scale precipitates. After aging at $723 \mathrm{~K}$ for $240 \mathrm{~min}$, the alloy is still in the recovery stage, and recrystallization does not occur. A large number of nano-sized coherent $\beta^{\prime}$ phases nucleate in the dislocation zone (Figure 8a) through the interaction with the dislocations, producing a good strengthening effect and simultaneously pinning the dislocations and dislocation cells (Figure 8b); this finally results in the enhancement of the alloy's recrystallization resistance capability. Zhang et al. [31] reported that the energy of the precipitate/matrix interface was increased by $\mathrm{Zr}$ in the ternary $\mathrm{Cu}-\mathrm{Cr}-\mathrm{Zr}$ alloy and composite, making it more difficult for dislocations to cut the coherent precipitates. Holzwarth et al. [38] found that the experimental data agrees much better with the assumption of an Orowan mechanism than with the shearing strengthening model, especially in the peak-hardened and slightly over-aged state of the $\mathrm{Cu}-\mathrm{Cr}-\mathrm{Zr}$ alloy. Consequently, the enhancement effect of the dispersed nanoparticles can be expressed by the following Orowan-Ashby equation in Equation (1) [39]:

$$
\tau_{0}^{c s}=\frac{0.81 \cdot G \cdot b \cdot \ln (d / b)}{2 \cdot \pi \cdot \sqrt{1-v} \cdot(\lambda-d)}
$$

where $G$ is the shear modulus of the matrix, $b$ is the modulus of the Burgers vector of the matrix, $d$ is the average radius of the particles, $v$ is the Poisson's ratio, $f$ is the volume fraction of the nano-sized precipitates, and $\lambda$ is the spacing between the particles. The latter can be expressed as Equation (2) [36]:

$$
\lambda=0.5 \cdot d \cdot \sqrt{\frac{3 \pi}{2 f}}
$$

The incremental increase of tensile strength caused by the Orowan mechanism can be expressed as:

$$
\Delta \sigma_{c s \max }=M \Delta \tau_{c s \max }
$$

where $M$ is the Taylor factor. Table 1 gives the parameters used in the yield strength determination where the Orowan bypass mechanism was considered. The tensile strength is increased by $136 \mathrm{MPa}$, as calculated by the Orowan mechanism. The tensile strength is increased by $119 \mathrm{MPa}$ after peak 
aging, and the calculation results are in good agreement with the experimental result in this work, which indicates the strength of the $\mathrm{Cu}-\mathrm{Cr}-\mathrm{Zr}$ alloy after the cold work meets the Orowan mechanism. The result is also in accordance with previous studies on $\mathrm{Cu}-\mathrm{Cr}-\mathrm{Zr}$ alloys [38].

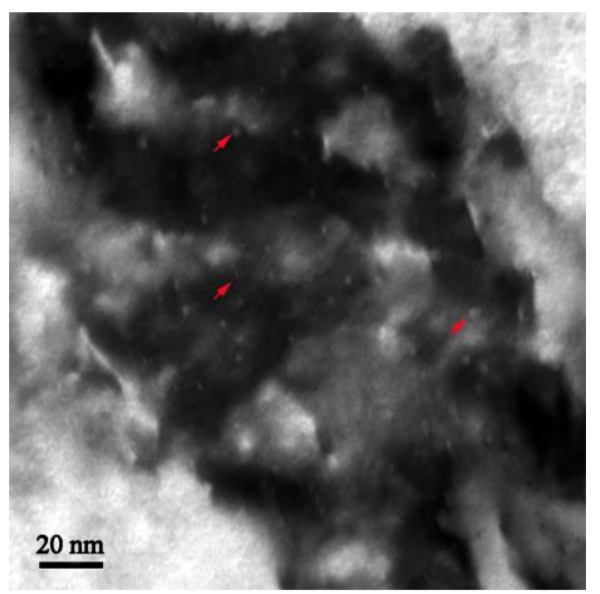

(a)

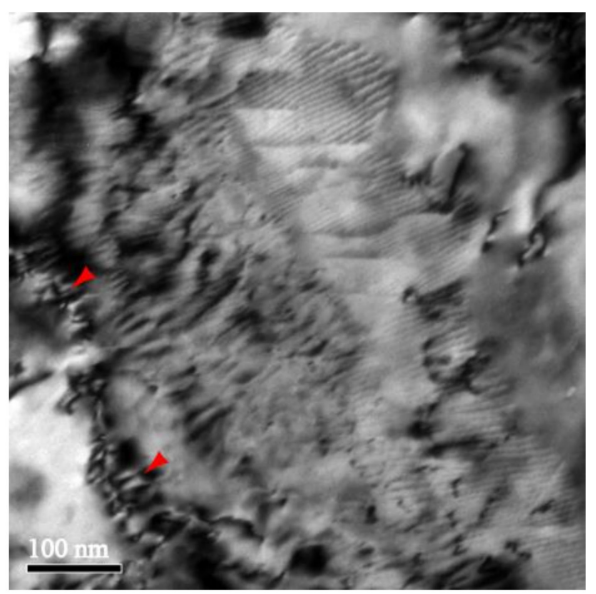

(b)

Figure 8. Bright-field transmission electron microscopy (TEM) micrographs and SAED of the studied alloy aged at $723 \mathrm{~K}$ for $240 \mathrm{~min}$ : (a) dislocations and second phase precipitates; and (b) pinned dislocations.

Table 1. The related parameters in the yield strength calculations, data from $[36,38,40]$.

\begin{tabular}{ccccc}
\hline Parameter & Description & Value & Units & References \\
\hline$G$ & Shear modulus of copper & 45.91 & $\mathrm{GPa}$ & {$[38]$} \\
$b$ & Burgers vector of copper & 0.2556 & $\mathrm{~nm}$ & {$[40]$} \\
$v$ & Poisson's ratio & 0.34 & - & {$[36]$} \\
$M$ & Taylor factor & 3.06 & - & {$[36]$} \\
$f$ & Volume fraction & $1.09 \%$ & - & This work \\
$R$ & Radius of the particles & 4 & $\mathrm{~nm}$ & This work \\
\hline
\end{tabular}

The fundamental reason for the electrical resistivity of a metal is that the lattice produces the scattering of electrons. The total resistivity of copper alloys is mainly caused by the intrinsic resistivity pure copper, solid solute atoms, and precipitated crystal defects (grain boundaries, dislocations, etc.) according to the theory of conductivity. Different types of crystal defects have different effects on the resistivity, from large to small, followed by solid solute atoms, phase precipitates, vacancies, dislocations, and other defects. After the aging treatment, a large number of solute atoms precipitate from the supersaturated solid solution, resulting in a significant decrease in the electron scattering effect. The size of the $\beta^{\prime}$ phases are in the range of 2-5 nm, whereas the mean free path of electrons of pure copper is about $42 \mathrm{~nm}$; the effect of precipitation on the conductivity of the alloy is therefore very small. In addition, a large number of tangled dislocations in the cold deformation state evolve into dislocation cells, sub-grains, and other sub-structures during the aging process, resulting in a significant reduction in the dislocation density of the dislocation cells and sub-grains (Figure $4 \mathrm{~b}$ ). As a result, one can conclude that the aging treatment can greatly increase the conductivity of the cold-worked Cur-Cr-Zr alloy, as shown in Figure $1 \mathrm{~b}$.

\subsection{The Effect of the Precipitation and Recrystallization Mechanisms on Recrystallization Resistance}

The recrystallization resistance of $\mathrm{Cu}-\mathrm{Cr}-\mathrm{Zr}$ alloys is highly related to the precipitate evolution and growth of precipitates. A huge number of finely distributed $\beta^{\prime}$ particles can pin the dislocations as well as hinder the grain boundary migration, thereby suppressing the nucleation and growth of the recrystallized grains. When annealed at $823 \mathrm{~K}$, the precipitates at the frontier of sub-grains start 
to coarsen and lose their coherence to transfer to the equilibrium phase $\beta$, leading to the coarsening as well as to the reduction of the number density of precipitates, as shown in Figure 6a,b. Due to the significant difference in the size of the secondary phases, a concentration gradient of the solute atoms exists among the secondary phases. The solute atom concentration around the fine secondary particles is higher than that of the coarse ones, which will cause the solute atoms around the fine secondary phases to migrate to the coarse ones, and which results in the re-dissolution of the fine secondary particles as well as in the growth of the coarse particles. During the process of secondary particle growth and number density reduction, the precipitates at the sub-grain boundary preferentially coarsen and lose their coherence (Figure $6 b$ ), which greatly reduces the grain boundary pinning effect. Recrystallization nucleation begins in the $\mathrm{Cu}-\mathrm{Zr}-\mathrm{Cr}$ alloy, and the hardness decreases. When annealed at $873 \mathrm{~K}$, the $\beta^{\prime}$ phase is fully replaced by $\beta$, and the density of the precipitates further decreases, as shown in Figure $6 c$,d; this, in turn, further reduces the capacity for the recrystallization process to be hindered.

Shear zones which have a certain angle with respect to the roll direction are formed after the $\mathrm{Cu}-\mathrm{Cr}-\mathrm{Zr}$ alloy is severely deformed via cold rolling. The shear deformation zones have a higher dislocation density than other regions, and the nucleation and growth of recrystallization occur more easily in the shear deformation region, as shown in Figures 3 and 4. The annealing temperature is a critical external factor for recrystallization, and the difference in the microstructure of different regions is a critical internal factor for inducing a difference in recrystallization behavior. Because of the lower deformation energy in the uniform deformation zones, more energy is required for the nucleation of recrystallization and, as a result, a higher temperature is needed for recrystallization. Unlike uniform deformation zones, higher dislocation densities and deformation are present in the shear deformation zone due to the severe shear deformation. Dislocation cell structures in the shear deformation zone rapidly form the new sub-grains during annealing, and recrystallization first occurs in the shear deformation zones, as shown in Figure 3c.

The growth of the recrystallized grains is accompanied by the formation and growth of annealing twins (marked by a triangle arrow in Figure 7a). It is shown that the growth of the recrystallized grains is restricted by the adjacent grains (Figure 7a). To release the internal deformation energy, twins with parallel interfaces form via the shear mode in order to lower the driving force for recrystallized grains to grow, as shown in Figure 7a. When multiple grains come together, dislocation storage zones are produced by the twins in the intersection of the grain boundary in order to lower the driving force for interface migration and hinder grain combination and growth, as shown in Figure 7b. Thus, the formation of twins can inhibit recrystallization, therefore enhancing the recrystallization resistance of the alloy. Theoretically, without the pinning of the secondary particles, the growth of twins can be infinite in the longitudinal direction. The secondary particles can block the growth of the twins and eventually hinder the recrystallized grains from growing. Due to the formation of twins, as shown in Figure 9a, the recrystallized grain size is uniform and the misorientation of the grains is about $60^{\circ}$, as shown in Figure $9 \mathrm{~b}$. This structure is a relatively stable state and reduces the hardness lost after full recrystallization. 


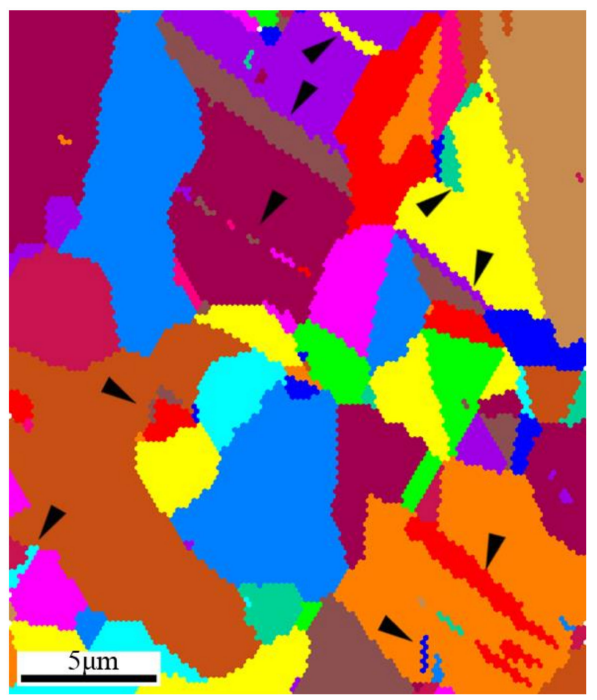

(a)

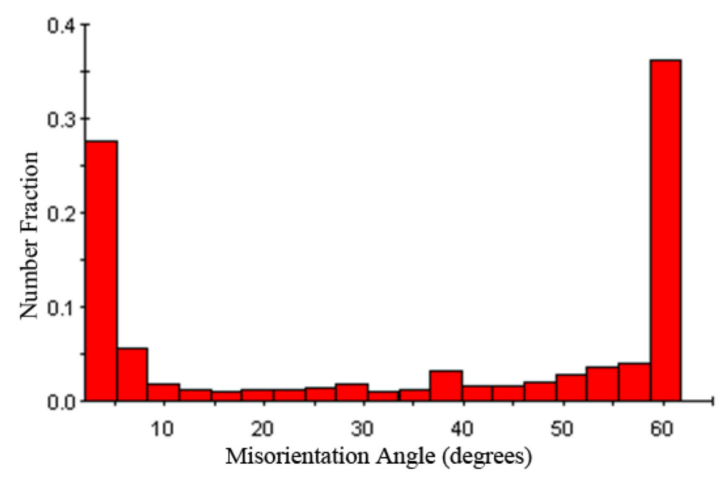

(b)

Figure 9. Typical electron backscattered diffraction (EBSD) substructures of recrystallization zone in a Cu-Cr-Zr alloy annealed at $823 \mathrm{~K}$ : (a) EBSD orientation imaging map; and (b) the distribution of grain boundary misorientation angles.

\section{Conclusions}

In this work, precipitation, recrystallization, and the evolution of twins during the heat treatment process in a $\mathrm{Cu}-\mathrm{Cr}-\mathrm{Zr}$ were studied by mechanical testing and microstructure observations. The main results are as follows:

1. A Cu-Cr-Zr alloy with a good combination of strength and conductivity can be obtained. The peak aged condition, with a tensile strength of $536 \mathrm{MPa}$ and electron conductivity of $85.3 \%$ IACS, can be achieved after the alloy undergoes a solid solution treatment at $1253 \mathrm{~K}$, before being cold-rolled with a reduction ratio of $70 \%$ and aged at $723 \mathrm{~K}$ for $240 \mathrm{~min}$. The increasing strength and the conductivity are mainly related to the formation of the transition phase $\beta^{\prime}$. A new type of fcc Cr-rich precipitate $\beta^{\prime}(\mathrm{II})$ is observed in the peak aged condition, which has an ordered structure and is coherent with the matrix, with the following OR: $[011]_{\beta^{\prime}(\mathrm{II})} / /[211]_{\mathrm{Cu}},\{200\}_{\beta^{\prime}(\mathrm{II})} / /\{-111\}_{\mathrm{Cu}}$ and $[111]_{\beta^{\prime}(\mathrm{II})} / /[100]_{\mathrm{Cu}},\{02-2\}_{\beta^{\prime}(\mathrm{II})} / /\{02-2\}_{\mathrm{Cu}}$.

2. The $\mathrm{Cu}-\mathrm{Cr}-\mathrm{Zr}$ alloy has a good recrystallization resistance. The dispersed distribution of the $\beta^{\prime}$ phase shows a good thermal stability during annealing, and can pin the dislocations and grain boundaries to hinder their migration, inhibiting recrystallization and thus enhancing the recrystallization resistance. When the $\beta^{\prime}$ particles are replaced by the coarsened $\beta$ particles, and when there is a reduction in the density of precipitates, the pinning effect on the dislocations and grain boundaries becomes weak, and recrystallization starts to occur in the $\mathrm{Cu}-\mathrm{Cr}-\mathrm{Zr}$ alloy.

3. Recrystallization nucleation and growth first occurs in the shear deformation zone due to its high deformation energy during the recrystallization process. The growth of the recrystallized grains, as well as the decrease in hardness during annealing, is hindered by the formation of annealing twins due to the release of deformation energy and the reduction of the driving force for interface migration.

Acknowledgments: The authors are grateful to the experimental assistance by Song Bo, and the valuable discussion with Wenzheng Zhang and Wei Wang. This work was financial supported by the international cooperation major Project of Ministry of Science and Technology of the People's Republic of China (2006DFA53240) and the Doctor Innovation Fund founded by Hunan Province Education Department (CX2011B109), as well as the Open-End Fund for the Valuable and Precision Instruments of Central South University (CSUZC20140010). 
Author Contributions: Xiaobo Chen and Feng Jiang conceived and designed the experiments; Jingyu Jiang, Pian $\mathrm{Xu}$, Mengmeng Tong, and Zhongqin Tang contributed to the experimental research work. Xiaobo Chen and Feng Jiang analyzed the data; Xiaobo Chen and Feng Jiang discussed the results and analysis with the other authors. Xiaobo Chen and Feng Jiang wrote the paper.

Conflicts of Interest: The authors declare no conflict of interest.

\section{References}

1. Igor, A.; Hans-Achim, K.; Mozhgan, G.; Mansour, M.; Lothar, W. Ultrafine-grained precipitation hardened copper alloys by swaging or accumulative roll bonding. Metals 2015, 5, 763-776.

2. Deng, L.P.; Han, K.; Wang, B.S.; Yang, X.F.; Liu, Q. Thermal stability of $\mathrm{Cu}-\mathrm{Nb}$ microcomposite wires. Acta Mater. 2015, 101, 181-188. [CrossRef]

3. Lei, R.S.; Wang, M.P.; Xu, S.Q.; Wang, H.P.; Chen, G.R. Microstructure, hardness evolution, and thermal stability mechanism of mechanical alloyed $\mathrm{Cu}-\mathrm{Nb}$ alloy during heat treatment. Metals 2016, 6, 194. [CrossRef]

4. Zhang, X.; Beach, J.A.; Wang, M.; Bellon, P.; Averback, R.S. Precipitation kinetics of dilute Cu-W alloys during low-temperature ion irradiation. Acta Mater. 2016, 120, 46-55. [CrossRef]

5. Zhang, D.D.; Bai, F.; Wang, Y.; Wang, J.G.; Wang, W.Q. Grain Refinement and Mechanical Properties of Cu-Cr-Zr Alloys with Different Nano-Sized TiCp Addition. Materials 2017, 10, 919. [CrossRef] [PubMed]

6. Alessandro, F.A.; Carlo, A.B.; Ausonio, T. Synthesis and structural analysis of Copper-Zirconium oxide. Metals 2016, 6, 195. [CrossRef]

7. Correia, J.B.; Davies, H.A.; Sellars, C.M. Strengthening in rapidly solidified age hardened Cu-Cr and Cu-Cr-Zr alloys. Acta Mater. 1997, 45, 177-190. [CrossRef]

8. Morozova, A.; Borodin, E.; Bratov, V.; Zherebtsov, S.; Belyakov, A.; Kaibyshev, R. Grain Refinement Kinetics in a Low Alloyed Cu-Cr-Zr Alloy Subjected to Large Strain Deformation. Materials 2017, 10, 1394. [CrossRef] [PubMed]

9. Hauf, U.; Kauffmann, A.; Kauffmann-Weiss, S.; Feilbach, A.; Boening, M.; Mueller, F.E.H.; Hinrichsen, V.; Heilmaier, M. Microstructure Formation and Resistivity Change in $\mathrm{CuCr}$ during Rapid Solidification. Metals 2017, 7, 478. [CrossRef]

10. Chbihi, A.; Sauvage, X.; Blavette, D. Atomic scale investigation of Cr precipitation in copper. Acta Mater. 2012, 60, 4575-4585. [CrossRef]

11. Dobatkin, S.V.; Gubicza, J.; Shangina, D.V.; Bochvar, N.R.; Tabachkova, N.Y. High strength and good electrical conductivity in $\mathrm{Cu}-\mathrm{Cr}$ alloys processed by severe plastic deformation. Mater. Lett. 2015, 153, 5-9. [CrossRef]

12. Zhang, Y.; Volinsky, A.A.; Hai, T.; Chai, Z.; Liu, P.; Tian, B.H.; Liu, Y. Aging behavior and precipitates analysis of the $\mathrm{Cu}-\mathrm{Cr}-\mathrm{Zr}-\mathrm{Ce}$ alloy. Mater. Sci. Eng. A 2016, 650, 248-253. [CrossRef]

13. Lai, R.L.; He, D.Q.; He, G.A.; Lin, J.Y.; Sun, Y.Q. Study of the microstructure evolution and properties response of a Friction-Stir-Welded Copper-Chromium-Zirconium alloy. Metals 2017, 7, 381. [CrossRef]

14. Luo, C.P.; Dahmen, U. Morphology and crystallography of $\mathrm{Cr}$ precipitates in a Cu-0.33 wt \% Cr alloy. Acta Mater. 1994, 42, 1923-1932. [CrossRef]

15. Fujii, T.; Nakazawa, H.; Kato, M.; Dahmen, U. Crystallography and morphology of nanosized Cr particles in a Cu-0.2\% Cr alloy. Acta Mater. 2000, 48, 1033-1045. [CrossRef]

16. Tang, N.Y.; Taplin, N.M.; Dunlop, G.L. Precipitation and aging in high-conductivity Cu-Cr alloys with additions of zirconium and magnesium. Mater. Sci. Technol. 1985, 1, 270-275. [CrossRef]

17. Batra, I.S.; Dey, G.K.; Kulkarni, U.D.; Banerjee, S. Microstructure and properties of a Cu-Cr-Zr alloy. J. Nucl Mater. 2001, 299, 91-100. [CrossRef]

18. Liu, P.; Kang, B.X.; Cao, X.G.; Huang, J.L.; Yen, B.; Gu, H.C. Aging precipitation and recrystallization of rapidly solidified Cu-Cr-Zr-Mg alloy. Mater. Sci. Eng. A 1999, 265, 262-267. [CrossRef]

19. Qi, W.X.; Tu, J.P.; Liu, F.; Yang, Y.Z.; Wang, N.Y.; Lu, H.M.; Zhang, X.B.; Guo, S.Y.; Liu, M.S. Microstructure and tribological behavior of a peak aged Cu-Cr-Zr alloy. Mater. Sci. Eng. A 2003, 343, 89-96. [CrossRef]

20. Su, J.H.; Dong, Q.M.; Liu, P.; Li, H.J.; Kang, B.X. Research on aging precipitation in a Cu-Cr-Zr-Mg alloy. Mater. Sci. Eng. A 2005, 392, 422-426. [CrossRef]

21. Batra, I.S.; Dey, G.K.; Kulkarni, U.D.; Banerjee, S. Precipitation in a Cu-Cr-Zr alloy. Mater. Sci. Eng. A 2003, 356, 32-36. [CrossRef] 
22. Xia, C.D.; Zhang, W.; Kang, Z.Y.; Jia, Y.L.; Wu, Y.F.; Zhang, R.; Xu, G.Y.; Wang, M.P. High strength and high electrical conductivity $\mathrm{Cu}-\mathrm{Cr}$ system alloys manufactured by hot rolling-quenching process and thermo-mechanical treatments. Mater. Sci. Eng. A 2012, 538, 295-301. [CrossRef]

23. Cheng, J.Y.; Shen, B.; Yu, F.X. Precipitation in a $\mathrm{Cu}-\mathrm{Cr}-\mathrm{Zr}-\mathrm{Mg}$ alloy during aging. Mater. Charact. 2013, 81, 68-75. [CrossRef]

24. Huang, F.X.; Ma, J.S.; Ning, H.L.; Geng, Z.T.; Liu, C.; Guo, S.M.; Yu, X.T.; Yu, W.T.; Li, H.; Lou, H.F. Analysis of phases in a Cu-Cr-Zr alloy. Scr. Mater. 2003, 48, 97-102.

25. Hatakeyama, M.; Toyama, T.; Yang, J.; Nagai, Y.; Hasegawa, M.; Ohkubo, T.; Eldrup, M.; Singh, B.N. 3D-AP and positron annihilation study of precipitation behavior in $\mathrm{Cu}-\mathrm{Cr}-\mathrm{Zr}$ alloy. J. Nucl. Mater. 2009, 386, 852-855. [CrossRef]

26. Su, J.H.; Liu, P.; Dong, Q.M.; Li, H.J.; Ren, F.Z. Recrystallization and precipitation behavior of Cu-Cr-Zr Alloy. J. Mater. Eng. Perform. 2007, 16, 490-493. [CrossRef]

27. Hughes, D.A.; Hansen, N.; Bammann, D.J. Geometrically necessary boundaries, incidental dislocation boundaries and geometrically necessary dislocations. Scr. Mater. 2003, 48, 147-153. [CrossRef]

28. Hu, T.; Chen, J.H.; Liu, J.R.; Liu, Z.R.; Wu, C.L. The crystallographic and morphological evolution of the strengthening precipitates in Cu-Ni-Si alloys. Acta Mater. 2013, 61, 1210-1219. [CrossRef]

29. Shi, Z.Z.; Zhang, W.Z. A transmission electron microscopy investigation of crystallography of $\tau-\mathrm{Mg}_{32}(\mathrm{Al}$, Zn) 49 precipitates in a Mg-Zn-Al alloy. Scr. Mater. 2011, 64, 201-204. [CrossRef]

30. Edwards, G.A.; Stiller, K.; Dunlop, G.L.; Couper, M.J. The precipitation sequence in Al-Mg-Si alloys. Acta Mater. 1998, 46, 3893-3904. [CrossRef]

31. Watanabe, C.; Monzen, R.; Tazaki, K. Mechanical properties of $\mathrm{Cu}-\mathrm{Cr}$ system alloys with and without $\mathrm{Zr}$ and Ag. J. Mater. Sci. 2008, 43, 813-819. [CrossRef]

32. Zhang, D.L.; Mihara, K.; Tsubokawa, S.; Suzuki, H.G. Precipitation characteristics of Cu-15Cr-0.15Zr in situ composite. Mater. Sci. Technol. 2000, 16, 357-363. [CrossRef]

33. Matsuda, K.; Uetani, Y.; Sato, T.; Ikeno, S. Metastable phases in an Al-Mg-Si alloy containing copper. Metall. Mater. Trans. A 2001, 32, 1293-1299. [CrossRef]

34. Marioara, C.D.; Nordmark, H.; Andersen, S.J.; Holmestad, R. Post- $\beta$ "phases and their influence on microstructure and hardness in 6xxx Al-Mg-Si alloys. J. Mater. Sci. 2006, 41, 471-478. [CrossRef]

35. Ninive, P.H.; Strandlie, A.; Gulbrandsen-Dahl, S.; Lefebvre, W.; Marioara, C.D.; Andersen, S.J.; Friis, J.; Holmestad, R.; Lovvik, O.M. Detailed atomistic insight into the $\beta$ "phase in Al-Mg-Si alloys. Acta Mater. 2014, 69, 126-134. [CrossRef]

36. Lei, Q.; Xiao, Z.; Hu, W.; Derby, B.; Li, Z. Phase transformation behaviors and properties of a high strength Cu-Ni-Si alloy. Mater. Sci. Eng. A 2017, 697, 37-47. [CrossRef]

37. Cuniberti, A.; Tolley, A.; Riglos, M.V.C.; Giovachini, R. Influence of natural aging on the precipitation hardening of an Al-Mg-Si alloy. Mater. Sci. Eng. A 2010, 527, 5307-5311. [CrossRef]

38. Holzwarth, U.; Stamm, H. The precipitation behaviour of ITER-grade $\mathrm{Cu}-\mathrm{Cr}-\mathrm{Zr}$ alloy after simulating the thermal cycle of hot isostatic pressing. J. Nucl. Mater. 2000, 279, 31-45. [CrossRef]

39. Mabuchi, M.; Higashi, K. Strengthening mechanism of Mg-Si alloy. Acta Mater. 1996, 44, 4611-4618. [CrossRef]

40. Gladman, T. Precipitation-hardening of metals. Mater. Sci. Technol. 1999, 15, 30-36. [CrossRef]

(C) 2018 by the authors. Licensee MDPI, Basel, Switzerland. This article is an open access article distributed under the terms and conditions of the Creative Commons Attribution (CC BY) license (http:/ / creativecommons.org/licenses/by/4.0/). 